6 Christian Püntener ${ }^{1}$, Jean-Paul Billon-Bruyat ${ }^{1}$, Daniel Marty ${ }^{1,2} \&$ Géraldine Paratte $^{1}$

$8{ }^{1}$ Section d'archéologie et paléontologie, Office de la culture, République et Canton du Jura, Porrentruy, Switzerland

9 22Naturhistorisches Museum Basel, Augustinergasse 2, 4001-Basel, Switzerland, martydaniel@hotmail.com

11 Corresponding author: christian.puentener@gmail.com, phone 00417948904 13, ORCID 0000-0001-5013-2106

\title{
13 Abstract
}

14 Recent excavations from the "Paléontologie A16" project brought to light thousands of dinosaur footprints and numer-

15 ous turtle remains from the Late Jurassic of Porrentruy (Swiss Jura Mountains). While most fossil turtles (Thalasso-

16 chelydia) were found in marly layers that were deposited in a coastal marine paleoenvironment, the dinosaur (theropods

17 and sauropods) tracks were found in laminites that were deposited in a tidal flat environment. Despite extensive explo-

18 ration, very few fossils were found in these dinosaur track-bearing laminites. On one occasion, a sub-complete turtle

19 shell (Plesiochelys bigleri) was discovered within the laminites, embedded just beneath an important sauropod track

20 level. The state of preservation of this specimen suggests that the turtle died on the tidal flat and was quickly buried.

21 This is the first evidence that these turtles occasionally visited tidal flat paleoenvironments. Moreover, the particular

22 configuration of the fossil turtle suggests that the shell was possibly trodden on by a large sauropod dinosaur.

24 Keywords Turtles, Sauropod tracks, Tidal flat, Taphonomy, Late Jurassic, Switzerland

25 Running Title Under the feet of sauropods

27 Institutional and locality abbreviations

28 MJSN JURASSICA Museum (formerly Musée jurassien des sciences naturelles), Porrentruy, Switzerland

29 CRO Combe Ronde, Chevenez, near Porrentruy, Switzerland

30 CRT Crat, Chevenez, near Porrentruy, Switzerland 


\section{Acknowledgements}

33 We thank the excavation team, the preparator of the specimen MJSN CRT007-2 (Pierre Bigler), the photographers

34 (Bernard Migy and Olivier Noaillon), the scientific illustrator (Pierre Widder), and the entire Paleontology A16 team.

35 Special thank goes to Jérémy Anquetin (JURASSICA Museum, Porrentruy) who significantly contributed to and im-

36 proved the manuscript. We furthermore thank the reviewers Nicole Klein and David Martill, as well as the scientific

37 editor Michael James Benton for their constructive inputs. This study was funded by the Federal Roads Office (FE-

38 DRO, 95\%) and the Republic and Canton of Jura (RCJU, 5\%). 


\section{Introduction and geological setting}

40 At the beginning of the $21^{\text {st }}$ century, the construction of Highway A16 through Canton Jura triggered a new paleonto-

41 logical project, called "Paléontologie A16". These recent excavations resulted in a rich and diverse vertebrate fossil col-

42 lection from the Kimmeridgian, including numerous coastal marine turtles (Püntener et al. 2017a and references there-

43 in), and extensive dinosaur tracksites (Castanera et al. 2018 and references therein). Most of the turtle remains come

44 from marly lithologies, while the dinosaur tracks were found in tidal carbonate laminites.

45 In this study we describe a partially-articulated turtle shell (MJSN CRT007-2) of Plesiochelys bigleri Püntener,

46 Anquetin and Billon-Bruyat, 2017a that was discovered just beneath an important sauropod trackway level and is one of

47 the rare articulated vertebrate remains from the dinosaur track-bearing laminites. The turtle was unearthed from the

48 Corbis Limestones during the field season of 2007 at the Chevenez-Crat site (CRT; 47 23'55.8' 'N $\left.7^{\circ} 01^{\prime} 43.65^{\prime \prime} \mathrm{E}\right)$,

49 near the village of Courtedoux, about 4 km southwest of Porrentruy (see figs. 1 and 2 in Püntener et al. 2017a). The

50 Corbis Limestones are especially rich in dinosaur footprints and exhibit four different track-bearing laminite intervals

51 (e.g., Razzolini et al. 2017). MJSN CRT007-2 was discovered within the lower track levels, which represent the lower-

52 most layers of the Corbis Limestones and are precisely dated to the Cymodoce ammonite zone (late Early Kim-

53 meridgian) (Comment et al. 2011, 2015). It is the only sub-complete and partially-articulated turtle carapace from the

54 Corbis Limestones. Other turtle remains are only occasionally discovered along with these trackways, as for example a

55 mandible and isolated shell bones, all of which probably belong to eurysternid turtles (cf. Püntener et al. 2017b). Most

56 turtle remains from the Porrentruy region come from the Lower Virgula Marls and the Banné Marls. This turtle fauna is

57 dominated by Plesiochelyidae and includes about 80 shells of Plesiochelys (Püntener et al. 2017a and references there-

58 in).

59

602 Sedimentology, ichnology and paleoenvironment

61 The lower laminite interval (levels 500-550), in which MJSN CRT007-2 was discovered, has been studied in detail by

62 Marty (2008) in Chevenez-Combe Ronde (CRO; 47²4'11.9' 'N 701'16.8'’E; Paratte et al. 2018a), a site situated only

$631 \mathrm{~km} \mathrm{NW}$ of Chevenez-Crat (Paratte et al. 2018c). The following information about this lower laminite interval is

64 therefore mainly based on the work of Marty (2008). A good correlation between the levels of the Crat and the Combe

65 Ronde sites has been observed in the field during the excavation of Chevenez-Crat.

Within the $0.65 \mathrm{~m}$ thick lower laminite interval of Chevenez-Combe Ronde, dinosaur tracks were found in eight

67 superimposed levels. The lowermost level (500, a subaerial paleosurface) represents the main track surface with a di-

68 verse ichnoassemblage of both sauropod and bipedal, tridactyl dinosaurs. In the seven superimposed upper levels (505,

$69510,515,520,530,540$, and 542) only sauropod tracks were found. The shell MJSN CRT007-2 was found between 
70 layers 520 and 530. However, the limits between the intermediate layers were not clear in the discovery area and the

71 remains could not be attributed more precisely, except for the xiphiplastra and the right peripheral 7 that were found in

72 the upper part of layer 530 (see Discussion).

73 At the Chevenez-Combe Ronde site, level 530 shows two generations of tracks (S1 and S2). Trackway S1 ex-

74 hibits shallow and quadrupedal tracks that were left in almost dry sediment. The tracks of S2 are relatively deep (up to

$7510 \mathrm{~cm}$ ) and on the average $48 \mathrm{~cm}$ long. They were left in "water-unsaturated to saturated sediment (layer 530), which

76 was penetrated and pushed besides by the foot in a way that the true track sensu stricto was left on top of, at that time

77 already consolidated, layer 528.“ (Marty 2008:127). Large and homogeneous displacement rims indicate that the dino-

78 saur placed a foot vertically into the sediment and removed it also vertically (Marty 2008). The average outward rota-

79 tion of the tracks of trackway S2 is $22^{\circ}$ for the left pes and $8.5^{\circ}$ for the right pes. Only pes tracks have been found in

80 trackway S2, implying that the manus tracks were subsequently overprinted by the pes tracks.

81 At the Chevenez-Crat site (where MJSN CRT007-2 comes from), only five isolated and undetermined dinosaur

82 tracks were discovered within levels 520-530 (Paratte et al. 2018c). They were all located in the same excavation unit

83 as the turtle MJSN CRT007-2 (unit 1;230 $\mathrm{m}^{2}$ ), but their exact location and stratigraphical position in the sediment has

84 not been documented.

85 The paleoenvironment, where the track-bearing laminites were deposited, is interpreted as a higher intertidal

86 mudflat to a lower supratidal flat that was located several hundred meters away from the coastline towards the open sea

87 or an internal lagoon (Marty 2008). According to Marty (2008), the exposure index at the time of the track formation of

88 the paleosurface 530 was not very high (about 60-90\%), in order to allow forming underprints with large and homoge-

89 neous displacement rims. This is also indicated by the absence of desiccation cracks in this layer. Marty (2008) fur-

90 thermore suggests that the conditions in this paleoenvironment were rather restricted and hostile, and that the tracks

91 were recorded during or rather at the end of rain periods or storm surges.

92

933 Systematic paleontology

94 See Püntener et al. (2017a) for Plesiochelys bigleri.

95

964 Description of the turtle shell

974.1 Carapace

98 Preserved are the anterior part of the carapace, the peripherals of the bridge region, as well as four disarticulated costals

99 and two disarticulated posterior peripherals (Figs. 1a, 1c, 2). The bone thickness is difficult to evaluate on the articulat- 
ed part of the carapace, but the disarticulated costals indicate relatively thin neurals, which corresponds to Plesiochelys

101 bigleri and contrasts with the thicker bones of Plesiochelys etalloni (Pictet and Humbert, 1857) (cf. Püntener et al.

102 2017a). Linear striations perpendicular to sutures are clearly visible, especially between the costals and between the

103 hyo- and hypoplastra.

104 The nuchal bone is complete. It is trapezoidal in outline and about twice as long as wide. The anterior nuchal notch is relatively deep compared to other specimens of Plesiochelys bigleri (cf. Püntener et al. 2017a, b) and stretches into the first peripherals. Only the first neural is preserved. It is elongated rectangular in outline and narrower and more rounded posteriorly than anteriorly.

Six costals are preserved (Fig. 2): costals 1-3 and costal 5 (only laterally) of the left side, and costals 1 and 3 of the right side. Both costals 1 are in situ and in articulation with neural one, the nuchal and the first three peripherals. The other four costals are disarticulated and their original positions in the sediment are unknown. The outlines of these costals correspond to the situation in Plesiochelys bigleri. The left costal 5 thickens ventrally towards the posterior, in order to form the inguinal buttress. This costal can be articulated with the left peripheral 8 , which is also in contact with the inguinal buttress.

Eight peripherals are preserved on the left side of the carapace. Peripherals 1-3 are still in situ and in articulation with the first costal. Peripherals 4 and 5 are slightly displaced towards the carapace midline by clockwise rotation. The plastral part of the fourth peripheral is broken off and turned up into the horizontal plane of the carapace. Similarly, the plastral parts of peripherals 5 and 6 curve up into the vertical plane. Peripherals 6 and 7 are approximately in situ, but the anteromedial part of peripheral 6 is broken and slightly displaced towards the carapace midline. Peripheral 8 is disarticulated, its original position in the sediment is unknown. It can be articulated with costal 5 (Fig. 2).

Seven peripherals are preserved on the right side of the carapace. As on the left side, the first three peripherals are in situ and in articulation with the first costal. Peripheral 4 is slightly rotated clockwise in the horizontal plane. Peripherals 5 and 6 are lower relative to the plastron plane and are slightly displaced and rotated counterclockwise in the horizontal plane. Their carapacial parts curve up vertically. Peripheral 7 is disarticulated, but still attached to the sediment. It is dislocated along the vertical plane and is now situated stratigraphically above (about $60 \mathrm{~mm}$ ) peripheral 6 (Fig. 1e). Peripheral 7 is also dislocated along the horizontal plane and is now situated about $120 \mathrm{~mm}$ posteriorly relative to its original place in the shell (Fig. 1e). It is rotated, so that its ventral side now faces anterodorsally. The scutes of the carapace bones follow essentially the pattern described for Plesiochelys bigleri (Figs. 1c, 2; cf. Püntener et al. 2017a). The three cervical scutes are well expressed, which is not very common in plesiochelyid turtles, where these sulci are often eroded (cf. Anquetin et al. 2014). The middle one is approximately quadrangular in outline 
and broader but shorter than the lateral ones. All longitudinal sulci of the cervicals are convex towards the carapace midline. Left peripheral 4 shows an abnormal scute pattern: the lateral pleural scute sulci do not join immediately with

132 the interpleural scute sulci, but lie parallel to each other towards (the disarticulated) costal 2. Right peripheral 4 shows a similar anomaly. As common in Plesiochelys bigleri, the preserved vertebral scutes cover about half to one third of the costal length. The scute sulcus between vertebrals 2 and 3 is strongly sinuous.

\subsection{Plastron}

137 With the exception of the two xiphiplastra, the plastron remains articulated and is relatively flat (Figs. 1b, 1d, 1e, 2).

138 The lateral region of the right hypoplastron is lower relative to the plastron plane and parts of the adjacent hyoplastron

139 and peripherals are broken off. The plastron is slightly rotated counterclockwise in the horizontal plane by about $7^{\circ}$

140 relative to the carapace (Fig. 3).

141 The anterior plastral lobe is well rounded. This is unusual for Plesiocheys bigleri, where this part of the plastron

142 is more often of sub-rectangular outline (cf. Püntener et al. 2017a). Epiplastral bulbs are absent. This, in turn, is typical

143 for Plesiocheys bigleri and contrasts to Plesiochelys etalloni, where these bulbs are usually better expressed (cf. Pün-

144 tener et al. 2017a). The entoplastron is subcircular in outline and relatively large compared to other specimens of this species (cf. Püntener et al. 2017b). As common in Plesiochelys bigleri and Plesiochelys etalloni, the hyoplastra are longer than wide (cf. Anquetin et al. 2014; Püntener et al. 2017a). The suture between the hyo- and hypoplastra has symmetric anteroposterior projections, an individual feature that can also be observed in other specimens of Plesiochelys bigleri (cf. Püntener et al. 2017a, b). in the sediment is known (Figs. 1e, 2). Contrary to peripheral 7, the xiphiplastra are almost not dislocated on the horizontal plane. They are mainly dislocated in the vertical plane and are now situated stratigraphically above (about 60 $\mathrm{mm}$ ) the hypoplastra, and are rotated around the transversal axis. The left xiphiplastron now stands almost vertically relative to the plastral plane, with the ventral side facing anteriorly. The right one now lies approximately in the horizontal plane with its ventral side facing dorsally. Püntener et al. 2017a, b). The gular scute is restricted to the epiplastra. The sulcus along the plastron midline is irregularly sinuous (visible on the right hyoplastron and the right xiphiplastron). There are four inframarginal scutes. The first

158 two are restricted to the hyoplastra (better visible on the left hyoplastron). As common for this species, the third one is 


\section{Discussion}

\subsection{On the presence of a partial turtle shell in dinosaur track-bearing laminites}

163 The discovery of a partial turtle shell in the dinosaur track-bearing laminites of the Porrentruy area is exceptional. Fos-

164 sils are generally scarce in these layers and only few other vertebrate remains have been found in the laminites, despite that these laminites were excavated over large areas and considerable quantities of marls were even screen-washed

166 (Marty 2008; Parratte et al. 2018b). Remains of terrestrial vertebrates are entirely missing. Fish (Pycnodontiformes) and crocodylomorphs are represented by a few isolated elements (mostly teeth). With the exception of the shell described

168 herein, turtles are known mostly by a few isolated shell elements and a small eurysternid mandible, found in the sediment filling of a theropod track (Püntener et al. 2017b). Not only are turtle and crocodylomorph remains rare in the laminites, but also their potential tracks are absent (Marty 2008). This suggests that these animals were not frequently present in this tidal flat paleoenvironments (or at least not during conditions favorable for preservation). Fossils of turtles

172 and crocodylomorphs are much more abundant in the more (coastal) marine Banné and Virgula Marls, which presuma173 bly were the preferred habitats of these animals.

174 The limestones from the Tithonian of Crayssac (Lot, France) represent a mudflat with sedimentation in the inter-

175 to supratidal area (Mazin et al. 1997, 2009) and are comparable with the dinosaur track-bearing laminites from the

176 Kimmeridgian of Porrentruy. The former are dominated by dinosaur and pterosaur tracks and yielded a few isolated 177 tracks of turtles and crocodilians. While some remains of crocodilians are present in Crayssac, turtle remains are very 178 scarce (Mazin et al. 2000), emphasizing again the exceptional discovery of MJSN CRT007-2 in the laminites of Por179 rentruy.

The shell bones of MJSN CRT007-2 are exquisitely preserved. There is no evidence of substantial transport or

181 predation on the bones, nor any external sign (e.g., bioclasts, sedimentary structures) suggesting that the shell could

182 have been transported by currents. Furthermore, the depositional environment of the Crat tracksite was situated relative-

183 ly far away from the coastline to the open sea or an internal lagoon (Marty 2008), which makes it unlikely that the turtle

184 drifted in as a carcasse. This is also corroborated by the absence of marine macroinvertebrate remains in these laminites.

185 Hence, the most likely scenario is that the turtle reached the tidal flat on its own and died there. The absence of weather-

186 ing, scavenging/predation marks, and incrustations on shell elements suggests a rapid burial. It should be noted that the

187 shell is preserved upside down, which suggests that it was turned over after the death of the turtle and before burial.

188 Modern marine turtles sometimes die because they get trapped in soft mudflats, in which case cranial and postcranial

189 elements quickly get dislocated notably thanks to the action of small scavengers, while the shells remain largely intact 
190 (Fretey 1981; Meyer 1991). This could also explain the absence of cranial and postcranial elements in MJSN CRT0071912.

The discovery of the shell MJSN CRT007-2 in dinosaur track-bearing laminites indicates that thalassochelydian

193 turtles occasionally visited these tidal flat environments. It is possible that females regularly crossed tidal flats to reach

194 the beach and lay eggs, although in that case we could expect turtle remains to occur more commonly in the laminites.

195 Therefore, MJSN CRT007-2 may represent a stranded individual that got stuck in a mudflat and/or dried out in the sun

196 while trying to reach the sea. Note that, in the absence of clearer evidence, this scenario remains speculative.

\subsection{On the particular disposition of the bones within the sediment}

199 The anterior part of the shell MJSN CRT007-2 is complete and articulated. In contrast, the middle part of the shell

200 (from peripheral 4 to peripheral 7) suffered more damage. Most notably, the lateral part of the right side of the plastron

201 was dorsoventrally crushed and peripherals $4-7$ on both sides exhibit various degrees of breakage, rotation and vertical

202 displacement (see Description above). The right peripheral 7 was separated from the shell and now lies about $120 \mathrm{~mm}$

203 behind and $60 \mathrm{~mm}$ above its natural position. It was also rotated with its ventral side now facing anterodorsally relative

204 to the natural orientation of the shell. Of the posterior part of the shell (behind peripherals 7 and 8), only the xiphiplastra are preserved. As described above, these two bones are disarticulated and displaced vertically, now lying about $60 \mathrm{~mm}$ above the level of the hyoplastra. Each of the xiphiplastra is rotated around the transversal axis.

These characteristics suggest that the shell was dorsoventrally compressed after burial. That the xiphiplastra and right peripheral 7 lie stratigraphically above the rest of the shell can either be explained by an upward reworking of these elements within the sediment, or by a downward displacement of the main part of the shell under the effect of the aforementioned compression. There is no indication that the vertical displacement of the xiphiplastra and right periph-

211 eral 7 is due to small-scale tectonic movements, so this third option can be discarded. In other circumstances, the syn-

212 sedimentary reworking of the xiphiplastra and right peripheral 7 would probably appear as the more likely explanation,

213 but here the mere vertical displacement of the xiphiplastra above their natural position and their rotation around the

214 transversal axis do not fit well with this scenario. In contrast, modern experiments have shown that trampling of bones

215 embedded in soft sediments can result in substantial breakage, horizontal and vertical displacement, and rotation of el-

216 ements in the sediment (Rozada et al. 2018). Given that the shell MJSN CRT007-2 is embedded in dinosaur track-

217 bearing laminites, trampling is an important taphonomical agent to consider.

\subsection{A trampled turtle shell?}


220 MJSN CRT007-2 was discovered at the Chevenez-Crat tracksite close to deep sauropod footprints (Marty 2008). Un-

221 fortunately, the footprints of levels 520-530 were poorly preserved in this locality and were not documented (Paratte et

222 al. 2018c). It is therefore impossible to compare the location of the turtle shell with that of the dinosaur footprints.

223 Chevenez-Crat can be correlated with the nearby important tracksite of Chevenez-Combe Ronde where levels

$224520-530$ and the associated dinosaur tracks are better preserved and documented. At the Chevenez-Combe Ronde

225 tracksite, layer 530 exhibits deep and well-defined sauropod tracks. Marty (2008) notably described some of these foot-

226 prints in detail (Fig. 4a). Walking on level 530, the sauropod left footprints that are up to $10 \mathrm{~cm}$ in depth and sometimes

227 reach the underlying level 528. A parallel with MJSN CRT007-2 could easily be drawn (Fig. 4b). The xiphiplastra and

228 the right peripheral 7 lie at the top of layer 530 and may indicate the level in which the shell was initially embedded.

229 Stepping on the already dead and buried turtle, a sauropod could have crushed the middle and anterior parts of the shell

230 and pushed them downward within the sediment. The xiphiplastra were broken off the rest of the plastron, rotated, but

231 remained approximately in situ. It is remarkable that the maximal vertical displacement between the xiphiplastra and

232 the plastron in MJSN CRT007-2 is about $7.5 \mathrm{~cm}$, which is in the range of the documented footprint depth at Chevenez-

233 Combe Ronde and actually corresponds to the depth measured on the footprint illustrated in Fig. 4. The rotation of the

234 plastron relative to the carapace in the horizontal plane can be explained by a slight horizontal friction of the dinosaur

235 foot, either at the time of placing the foot onto the turtle shell or when taking it off (Fig. 5).

\section{6 Conclusions}

238 Fossils in general and vertebrate remains in particular are scarce in the Kimmeridgian dinosaur track-bearing laminites

239 of the Porrentruy area. The discovery of a relatively complete turtle shell in these layers is therefore noteworthy. This

240 specimen demonstrates that thalassochelydian turtles living in the nearby coastal waters occasionally crossed the vast

241 tidal flats on which dinosaurs roamed. The turtle shell described herein is also interesting because of the remarkable

242 disposition of the fossilized bones within the sediment. Although we have no definitive evidence of this, it is probable

243 that this shell was trampled upon by a sauropod dinosaur after burial. Examples of trampled vertebrates are rarely doc-

244 umented in the fossil record. We are aware of only one other case: Cabral-Perdomo (1995, 2013) reports a flamingo

245 skeleton from Tepexi de Rodríguez (Puebla, Mexico; a lacustrine limestone site from the Plio-Pleistocene) that is asso-

246 ciated with a camel track. Lockley (1991) suggests that the already dead flamingo was stepped on by a camel that

247 crossed a lake bed. In contrast to MJSN CRT007-2, the flamingo can directly be associated with a track of the

248 trackmaker, but the effect on the trampled fossil is less clearly visible than in the turtle MJSN CRT007-2, the latter be-

249 ing clearly mechanically broken. Preliminary experiments in soft sediments revealed that trampled bones bore scratch 
250 marks on their surface, but the identification of these marks remains to be formalized (Rozada et al. 2018). When this is 251 done, it would be interesting to look for potential trampling scratch marks on MJSN CRT007-2 in order to see if our 252 preliminary interpretation can be corroborated. 


\section{References}

254 Anquetin, J., Püntener, C., \& Billon-Bruyat, J.-P. (2014). A taxonomic review of the Late Jurassic eucryptodiran turtles from the Jura Mountains (Switzerland and France). PeerJ, 2, e369, https://doi.org/10.7717/peerj.369.

Cabral-Perdomo, M. A. (1995). Los icnofósiles de vertebrados terrestres del Terciario Tardío del área de Tepexi de Rodríguez, Estado de Puebla. Tesis de Licenciatura, Universidad Nacional Autónoma de México, Facultad de Ciencias, Mexico City.

Cabral-Perdomo, M. A. (2013). Icnofósiles de vertebrados terrestres del Cenozoico Tardío en el área de Pie de Vaca, Tepexi de Rodríguex, Estado de Puebla. Paleontología Mexicana, 3, 51-58.

Castanera, D., Belvedere, M., Marty, D., Paratte, G., Cattin, M., Lovis, C., \& Meyer, C. A. (2018). A walk in the maze: variation in Late Jurassic tridactyl dinosaur tracks from the Swiss Jura Mountains (NW Switzerland). PeerJ, 6, e4579, https://doi.org/10.7717/peerj.4579.

Comment, G., Ayer, J., \& Becker, D. (2011). Deux nouveaux membres lithostratigraphiques de la Formation de Reuchenette (Kimméridgien, Ajoie, Jura suisse) - Nouvelles données géologiques et paléontologiques acquises dans le cadres de la construction de l'autoroute A16 (Transjurane). Swiss Bulletin für angewandte Geologie, 16, 3-24.

Comment, G., Lefort, A., Koppka, J., \& Hantzpergue, P. (2015). Le Kimméridgien d'Ajoie (Jura, Suisse): lithostratigraphie et biostratigraphie de la Formation de Reuchenette. Revue de Paléobiologie, 34, 161-194.

270 Fretey, J. (1981). Tortues marines de Guyane. Paris: Éditions du Léopard d'or.

271 Lockley, M. G. (1991). Tracking dinosaurs: a new look at an ancient world. Cambridge: Cambridge University Press.

272 Marty, D. (2008). Sedimentology, taphonomy, and ichnology of Late Jurassic dinosaur tracks from the Jura carbonate platform (Chevenez-CombeRonde tracksite, NW Switzerland): insights into the tidalflat palaeoenvironment and dinosaur diversity, locomotion, and palaeoecology. GeoFocus, 21, 1-278.

Mazin, J.-M., Billon-Bruyat, J.-P., \& Padian, K. (2009). First record of a pterosaur landing trackway. Proceedings of the Royal Society B: Biological Sciences, 276(1674), 3881-3886.

280 Mazin, J.-M., Hantzpergue, P., Bassoullet, J.-P., Lafaurie, G., \& Vignaud, P. (1997). Le gisement de Crayssac (Tithonien inférieur, Querçy, Lot, France): découverte de pistes de dinosaures en place et premier bilan

284 Meyer, C. A. (1991). Burial experiments with marine turtle carcasses and their paleoecological significance. Palaios, 285 6(1), 89-96. 
Paratte, G., Lapaire, M., Lovis, C., \& Marty, D. (2018a). Traces de dinosaures jurassiques - Chevenez-Combe Ronde (Catalogues du patrimoine paléontologique jurassien - A16). Porrentruy: Office de la culture - Paléontologie A16.

289 Paratte, G., Lapaire, M., Lovis, C., \& Marty, D. (2018b). Traces de dinosaures jurassiques - Contexte et méthode (Catalogues du patrimoine paléontologique jurassien - A16). Porrentruy: Office de la culture - Paléontologie A16.

291 Paratte, G., Lapaire, M., Lovis, C., \& Marty, D. (2018c). Traces de dinosaures jurassiques - Chevenez-Crat (Cata-

292 logues du patrimoine paléontologique jurassien - A16). Porrentruy: Office de la culture - Paléontologie A16.

293 Pictet, F.-J., \& Humbert, A. (1857). Description d'une émyde nouvelle (Emys Etalloni) du terrain jurassique supérieur des environs de St-Claude. In F.-J. Pictet (Ed.), Matériaux pour la paléontologie suisse, Première série (pp. 1-

10). Genève: J. Kessmann.

296 Püntener, C., Anquetin, J., \& Billon-Bruyat, J.-P. (2017a). The comparative osteology of Plesiochelys bigleri n. sp., a new coastal marine turtle from the Late Jurassic of Porrentruy (Switzerland). PeerJ, 5, e3482,

https://doi.org/10.7717/peerj.3482.

299 Püntener, C., Anquetin, J., \& Billon-Bruyat, J.-P. (2017b). Vertébrés mésozoïques - Tortues (Catalogues du patrimoine paléontologique jurassien - A16). Porrentruy: Office de la culture - Paléontologie A16.

301 Razzolini, N. L., Belvedere, M., Marty, D., Paratte, G., Lovis, C., Cattin, M., \& Meyer, C. A. (2017). Megalosauripus transjuranicus ichnosp. nov. A new Late Jurassic theropod ichnotaxon from NW Switzerland and implications for tridactyl dinosaur ichnology and ichnotaxomy. PLoS ONE, 12(7), e0180289, https://doi.org/10.1371/journal.pone.0180289.

305 Rozada, L., Allain, R., \& Tournepiche, J. F. (2018). Trampling experiments on bones in fine and soft sediments. Quaternaire. Revue de l'A ssociation française pour l'étude du Quaternaire, 29(1), 39-44. 


\section{Figures}

308

a
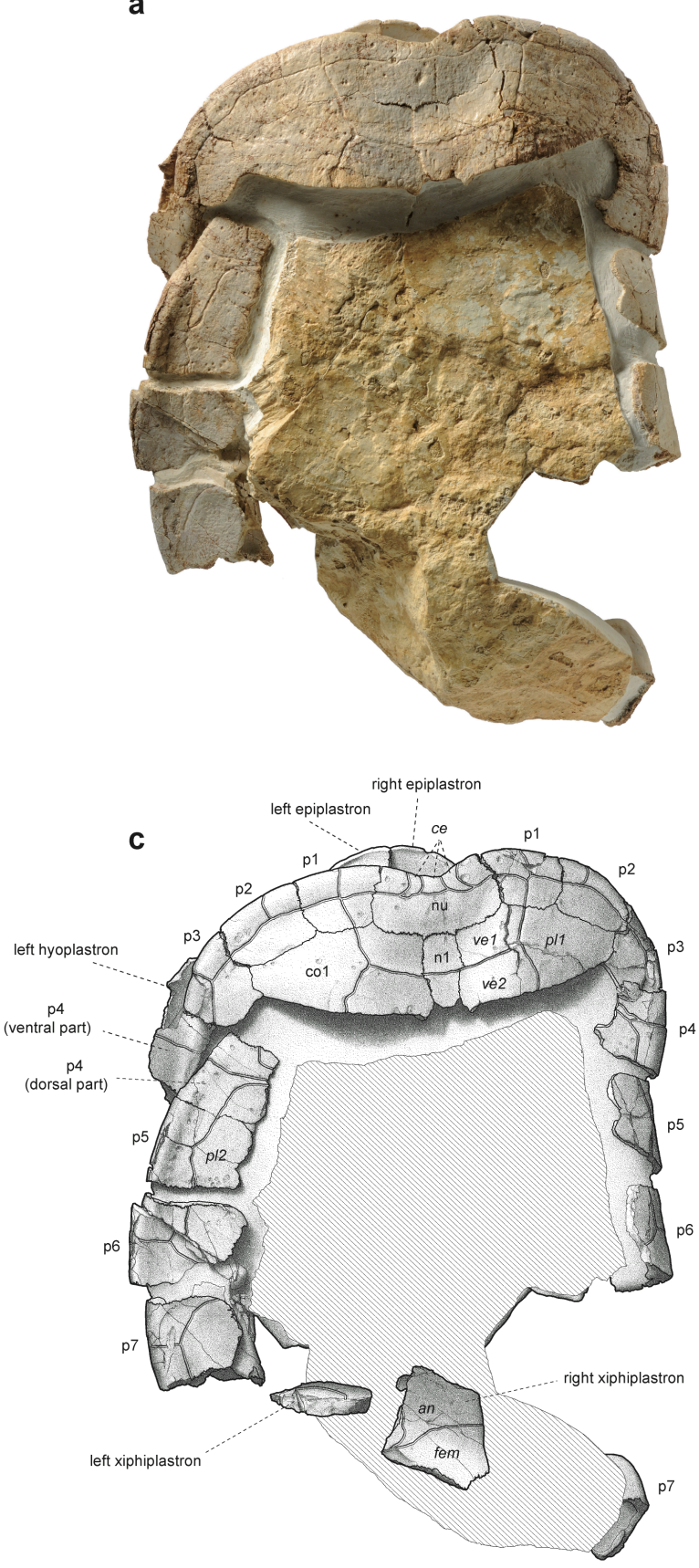

b

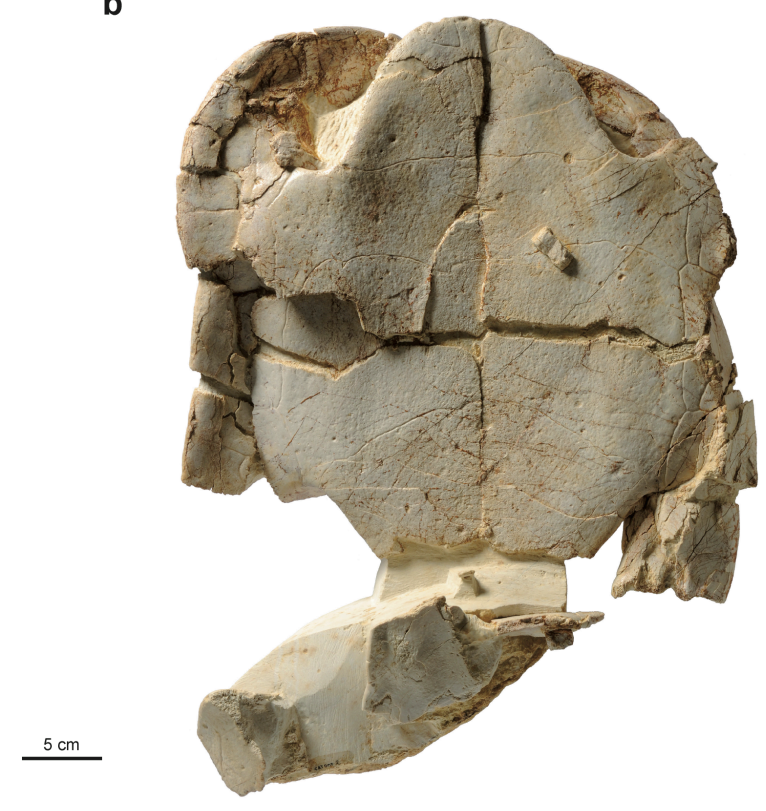

d

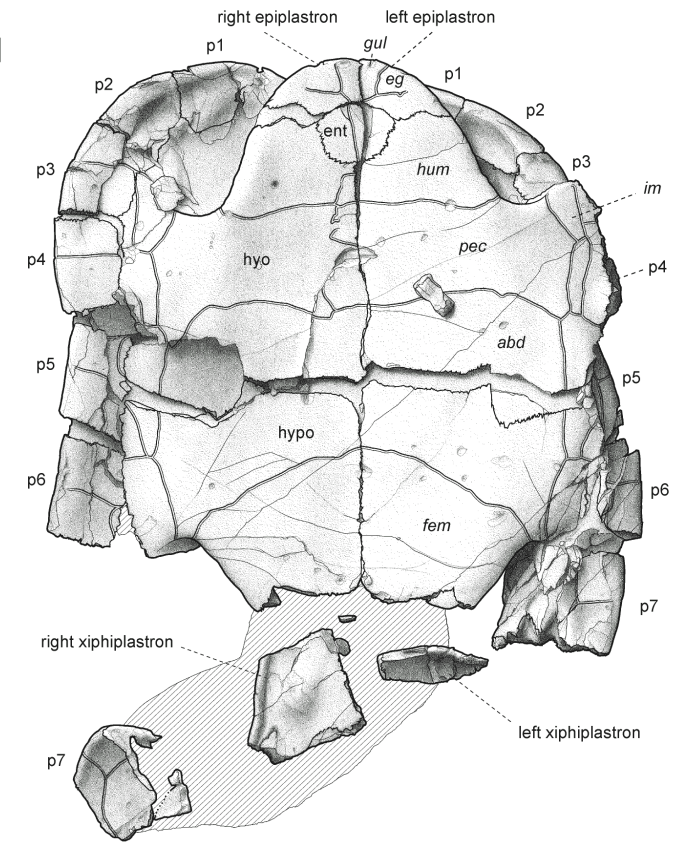

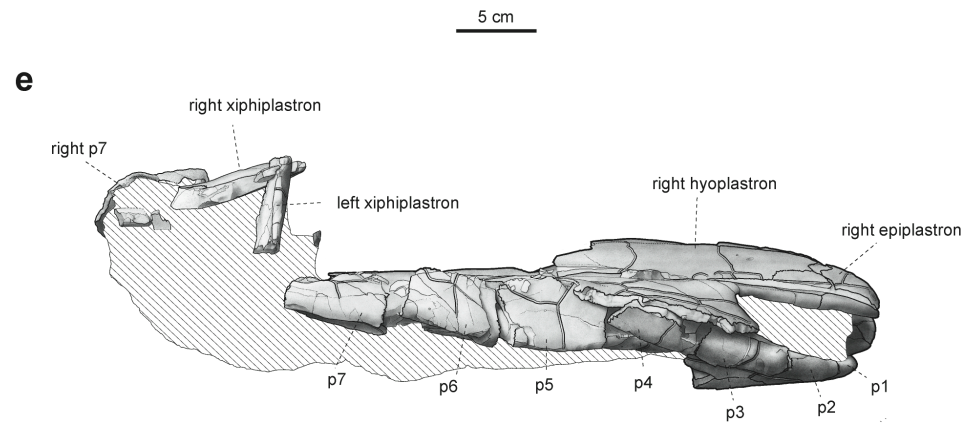


310 Fig. 1 MJSN CRT007-2, Plesiochelys bigleri (Kimmeridgian, Porrentruy, Switzerland). Photographs of the shell in dor311 sal (a) and ventral (b) view, and drawing of the shell in dorsal (c), ventral (d), and left lateral (e) view. Line width indi312 cates natural borders (thick lines), bone sutures (intermediate lines) and fractures (thin lines); double lines indicate scale 313 sulci. Abbreviations: abd, abdominal; an, anal; ce, cervical; co, costal; eg, extragular; ent, entoplastron; fem, femoral;

314 gul, gular; hum, humeral; im, inframarginal; n, neural; nu, nuchal; p, peripheral; pec, pectoral; pl, pleural; hyo, hyoplas315 tron; hypo, hypoplastron; ve, vertebral 

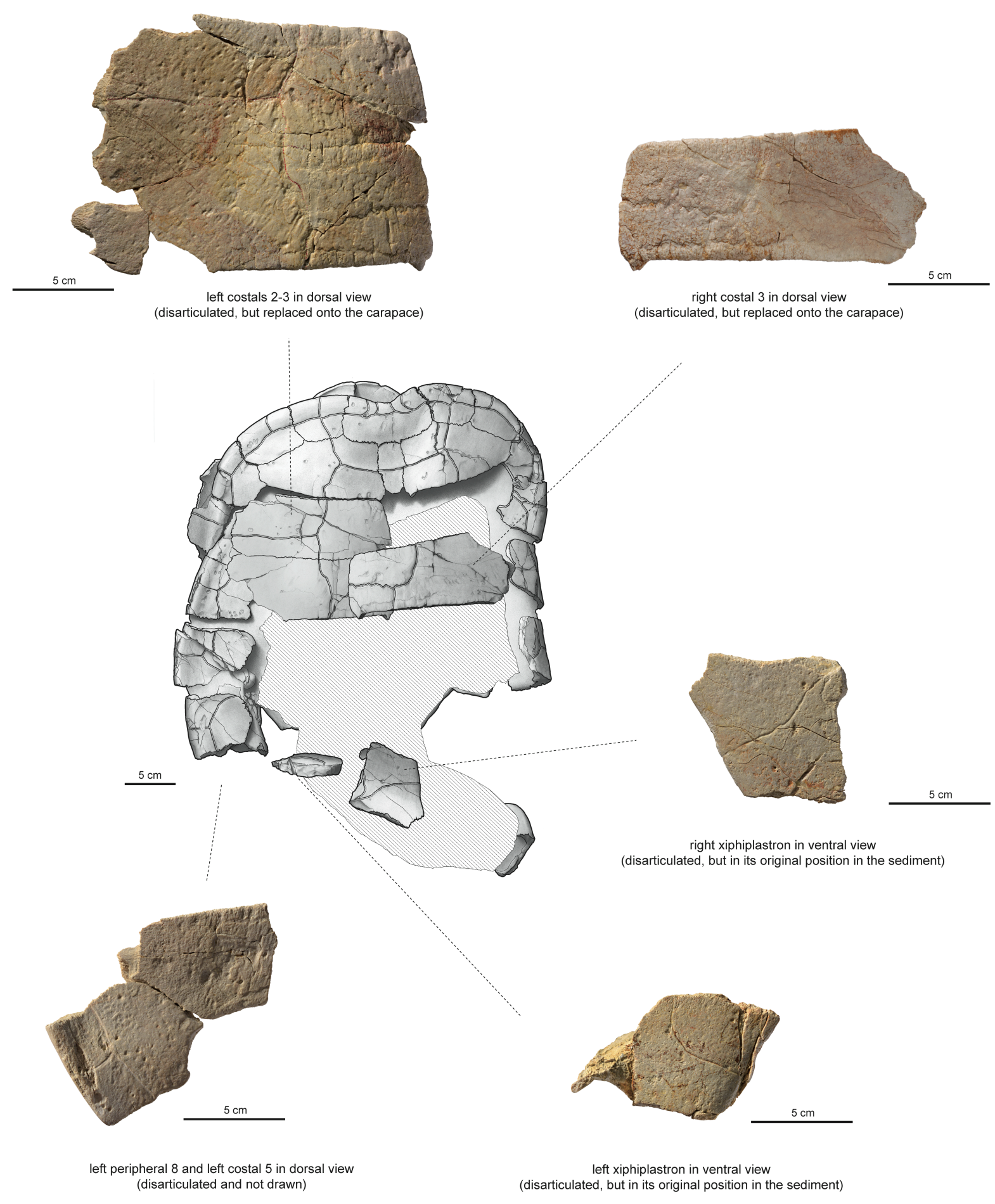

317 Fig. 2 MJSN CRT007-2, Plesiochelys bigleri (Kimmeridgian, Porrentruy, Switzerland). Drawing of the carapace in

318 dorsal view (with three disarticulated costals replaced onto the carapace); and photographs of the disarticulated ele319 ments 


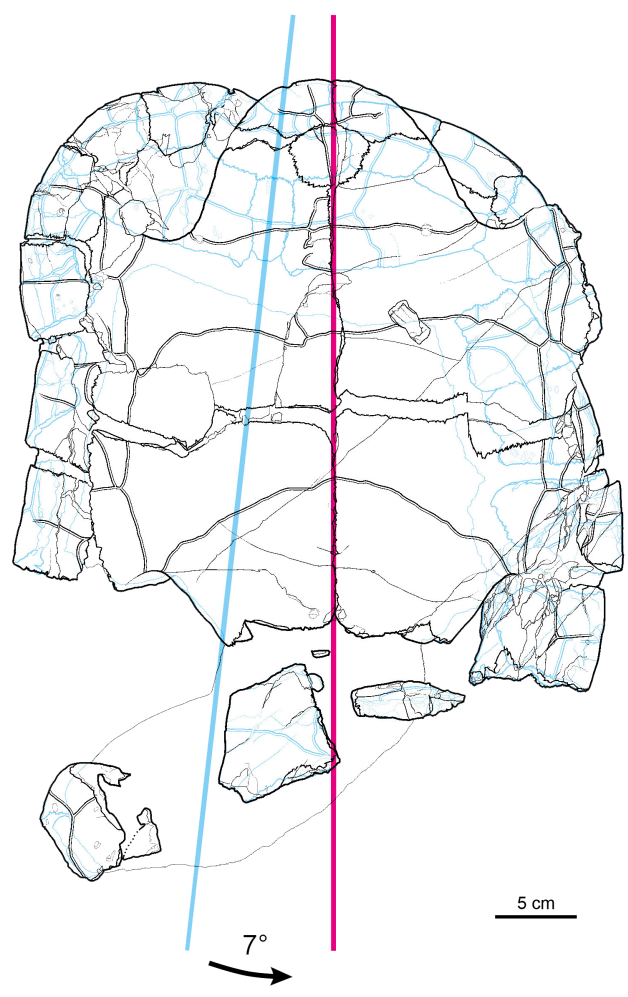

321 Fig. 3 MJSN CRT007-2, Plesiochelys bigleri (Kimmeridgian, Porrentruy, Switzerland). Illustration of the shift between

322 the plastron and the carapace. The plastron is in black, its main axis in red; the underlying carapace and its axis are in

323 blue

324
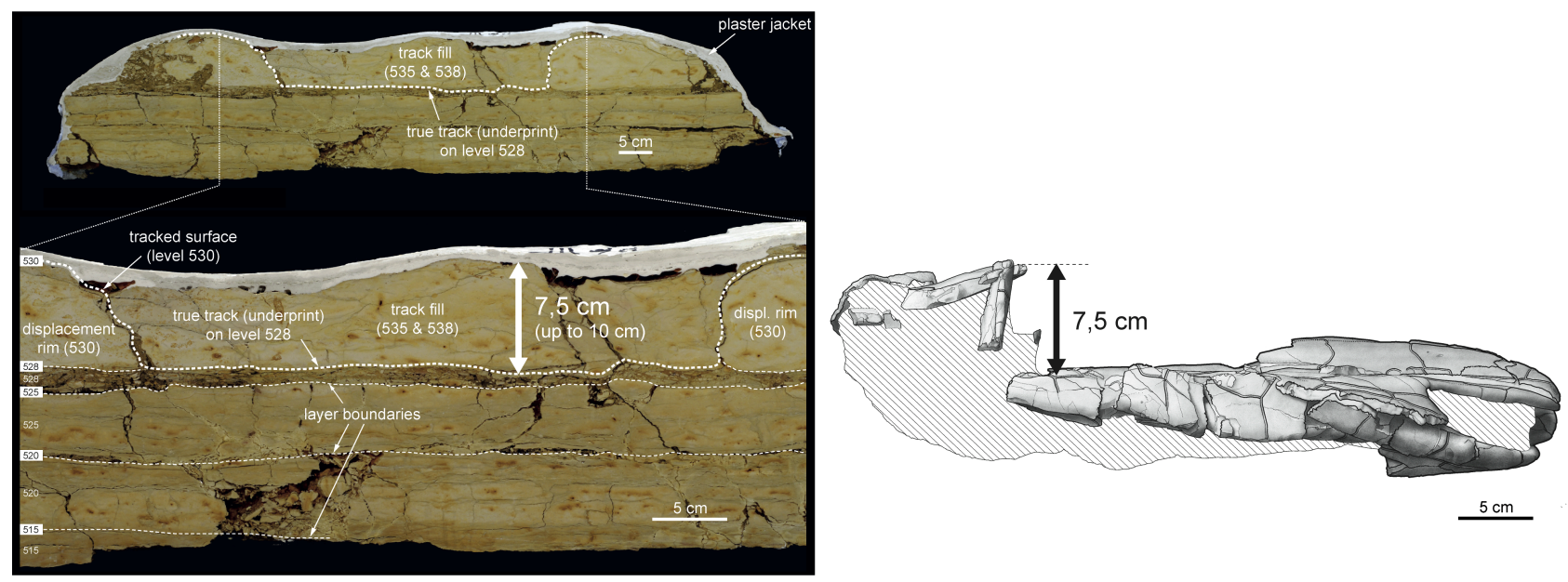

b

326 Fig. 4 Comparison of a sauropod pes track with the taphonomic condition of the turtle MJSN CRT007-2. (a) cross-

327 section of sauropod track RP2 of the pes-only trackway S2 of level 530 (Chevenez-Combe Ronde tracksite; modified

328 from Marty 2008); (b) MJSN CRT007-2 in lateral left view (Chevenez-Crat tracksite). Note that there is no direct cor-

329 relation of this specific sauropod track (a) and the turtle MJSN CRT007-2 (b). Hatchings represent sediment 

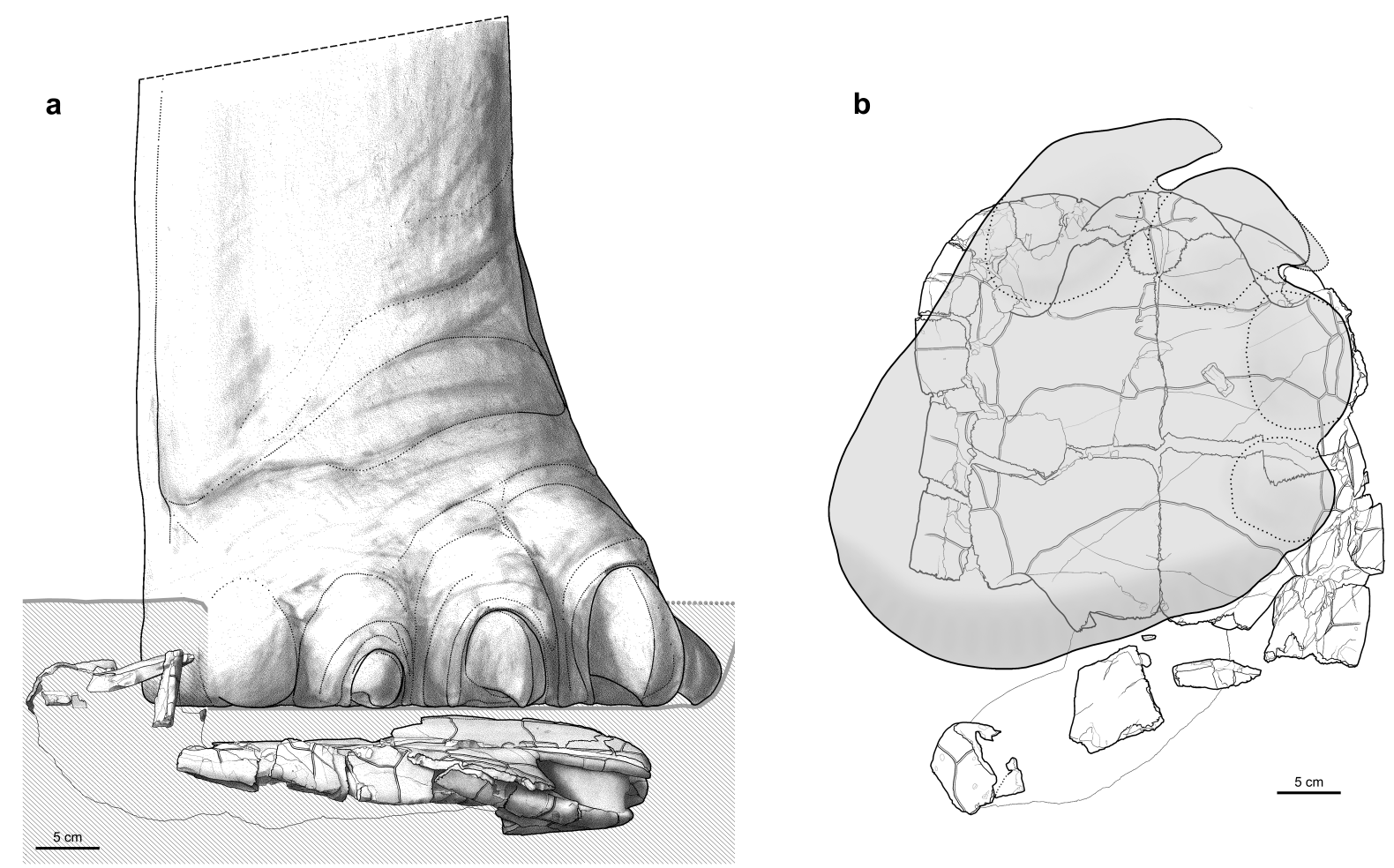

331 Fig. 5 MJSN CRT007-2, Plesiochelys bigleri (Kimmeridgian, Porrentruy, Switzerland). (a) suggested reconstruction of 332 a sauropod foot stepping onto the turtle, thereby pushing the main shell further down into the sediment and provoking 333 the disarticulation and rotation of the two xiphiplastra and the right peripheral 7. The turtle shell is in lateral left view. 334 Hatchings represent sediment. (b) suggested placement of the sauropod foot on the turtle shell. View from above 